\title{
Investigation of the catalytic activity of extracted and smoothly calcined arenesulfonic modified SBA-15 materials
}

\author{
Sami Habib ${ }^{\text {a }}$, Petra Salamé ${ }^{\text {a }}$, Franck Launay ${ }^{\mathrm{a}, *}$, Virginie Semmer-Herledan ${ }^{\mathrm{a}}$, \\ Olivier Marie $^{b}$, Wei Zhao ${ }^{c}$, Nataša Novak Tušar ${ }^{\mathrm{d}}$, Antoine Gédéon ${ }^{\mathrm{a}, *}$ \\ ${ }^{a}$ Laboratoire Systèmes Interfaciaux à l'Echelle Nanométrique, CNRS-UMR 7142, Université Pierre et Marie Curie, \\ Case 196, 4 Place Jussieu, 75252 Paris Cedex 05, France \\ ${ }^{\mathrm{b}}$ Laboratoire Catalyse et Spectrochimie, CNRS-UMR 6506, ENSICAEN, 6 Bd du Maréchal Juin, 14050 Caen Cedex, France \\ ${ }^{\mathrm{c}}$ Research Center for Eco-Environmental Sciences, Chinese Academy of Sciences, 100085 Beijing, PR China \\ ${ }^{\mathrm{d}}$ National Institute of Chemistry, Hajdrihova 19, 1000 Ljubljana, Slovenia \\ Received 12 December 2006; received in revised form 14 February 2007; accepted 16 February 2007 \\ Available online 22 February 2007
}

\begin{abstract}
A thorough FTIR investigation of the thermal stability of arenesulfonic modified SBA-15 solids revealed that most of the organic functional groups are preserved until $400^{\circ} \mathrm{C}$. These results have been confirmed by the thermogravimetric analyses of the corresponding materials calcined at $200{ }^{\circ} \mathrm{C}(\mathrm{EC}-200)$ or $400^{\circ} \mathrm{C}$ (EC-400), respectively. Such studies showed that the smoother calcination procedure (200 $\left.{ }^{\circ} \mathrm{C}\right)$ is appropriate in order to complete the removal of Pluronic P123 in the extracted sample (E). Moreover, it can be noticed that such calcination treatment did not alter tremendously the catalytic performances of the resulting solids. Both E and EC-200 materials exhibited high activities in the liquid phase condensation of 2-methylfuran with acetone and in the decomposition of cumene hydroperoxide into phenol.
\end{abstract}

(C) 2007 Elsevier B.V. All rights reserved.

Keywords: Mesoporous silica; Arenesulfonic acids; Thermal stability; Liquid phase condensation; Cumene hydroperoxide

\section{Introduction}

Structured mesoporous aluminosilicates such as Al-MCM41 and Al-SBA-15 have attracted a great deal of attention due to their potential applications as acid catalysts for bulky substrates [1]. However, the rather weak acidity of these solids compared to conventional zeolites is a limiting factor [2,3]. Besides the synthesis of zeolite/mesoporous composites [4-7], other mesostructured acid solids have been obtained through the functionalisation of silica with strong acidic groups like the sulfonic ones. There are a lot of literature data dealing with the covalent attachment of alkanesulfonic or arenesulfonic groups [8-36] to ordered silica materials (MCM-41, SBA-15 ...) and their application in acid catalysis. The direct sulfonation of alkyl or aryl groups anchored to the support is not a widespread method [8-10]. In most of the cases, the

\footnotetext{
* Corresponding authors. Tel.: +3314427 7143 .

E-mail addresses: franck.launay@upmc.fr (F. Launay), Antoine.gedeon@upmc.fr (A. Gédéon).
}

sulfonic acid functions are introduced by the rather unselective oxidation of mercaptopropyl groups onto silica [10-31]. The direct introduction of a stronger function brought by the 2-(4-chlorosulfonylphenyl)ethyltrimethoxysilane (CSPTMS) is also considered with a growing attention [11,12,16-22]. Co-condensation methods [10-13,15-19,23-29] are preferred over grafting procedures $[14,30-34]$ due to the better distribution of the functions throughout the material. The removal of the organic surfactants, cetyltrimethylammonium halide and Pluronic P123, used as structure-directing agents (for MCM-41 [10,13,25,26,28,29,33,35] and SBA-15 [10-12,15,17-19,27], respectively) is usually conducted via their extractions by $\mathrm{HCl} /$ ethanol and ethanol, respectively. The materials thus prepared have been successfully tested in a large number of acid-catalysed reactions such as esterification $[8,13,15,18,19,23,25,30,35,36]$, etherification $[9,27]$, alkylation [10], condensation $[23,25,31-33]$ and different rearrangement processes $[10,12,16,19,22]$.

The objective of the present article was to take advantage of a smooth calcination step performed on the extracted sample in 
order to improve the removal of the surfactant. Such a procedure, never described before, was proposed in agreement with the results of FTIR and TGA studies indicating the thermal stability of the arenesulfonic groups. The SBA-15 type material considered, $\mathrm{SBA}-\mathrm{ar}-\mathrm{SO}_{3} \mathrm{H}$, was obtained by the co-hydrolysis of 2-(4-chlorosulfonylphenyl)ethyltrimethoxysilane (CSPTMS) and tetraethylorthosilicate (TEOS) and characterised by elemental analyses and MAS ${ }^{33} \mathrm{~S}$ NMR. Acid-catalysed reactions like the condensation of 2-methylfuran (MF) and acetone as well as the decomposition of cumene hydroperoxide (CHP) were tested in order to investigate the influence of the procedure used for the surfactant removal.

\section{Experimental}

\subsection{Sample preparation}

The arenesulfonic acid-functionalised SBA-15 material was prepared following a co-hydrolysis procedure [12,19]: four grams of Pluronic $\mathrm{P} 123\left(\mathrm{EO}_{20} \mathrm{PO}_{70} \mathrm{EO}_{20}, M_{\mathrm{av}}=5800\right.$, Aldrich) were dissolved in $125 \mathrm{~g}$ of $1.9 \mathrm{M} \mathrm{HCl}$. After the complete dissolution of the surfactant $\left(3 \mathrm{~h}\right.$ at $\left.40^{\circ} \mathrm{C}\right)$, TEOS $(0.034 \mathrm{~mol}$, Fluka) was added and the resulting mixture equilibrated at $40^{\circ} \mathrm{C}$ for $45 \mathrm{~min}$ (prehydrolysis step). Then, $3 \mathrm{~mL}$ of a dichloromethane solution of 2-(4-chlorosulfonylphenyl)ethyltrimethoxysilane (50\%, ABCR, $6 \mathrm{mmol}$ ) and $1.85 \mathrm{~mL}$ of aqueous $\mathrm{H}_{2} \mathrm{O}_{2}(30$ wt. \%, Carlo Erba) were slowly added to the mixture of TEOS and P123. The resulting solution was stirred at $40^{\circ} \mathrm{C}$ for $20 \mathrm{~h}$, then transferred into a polypropylene bottle and heated at $100^{\circ} \mathrm{C}$ for $24 \mathrm{~h}$ under static conditions. The solid product was recovered by filtration, washed several times with distilled water and dried at room temperature overnight. The removal of the surfactant from the $a s$-synthesised material was performed by refluxing the solid in ethanol for $24 \mathrm{~h}(1.5 \mathrm{~g} / 400 \mathrm{~mL})$. A more complete elimination of the Pluronic P123 was investigated through the combination of the extraction step with different calcination treatments (calcination under air flow $\left(9 \mathrm{~L} \mathrm{~h}^{-1}\right)$ at 200,400 or $500{ }^{\circ} \mathrm{C}$ for $6 \mathrm{~h}$ $\left(24^{\circ} \mathrm{Ch}^{-1}\right)$ ). The resulting solids are named $\mathrm{E}$ (for extracted samples) or EC-T (for extracted and calcined solids) where $\mathrm{T}$ stands for the calcination temperature $\left({ }^{\circ} \mathrm{C}\right)$.

\subsection{Characterisation techniques}

The solids were characterised by X-ray diffraction on a Bruker D8 Advanced diffractometer using $\mathrm{Cu} \mathrm{K} \alpha$ radiation in the range between $0.5^{\circ}$ and $5^{\circ}(2 \theta)$. Nitrogen sorption experiments were carried out at $-196^{\circ} \mathrm{C}$ on a Micromeritics ASAP 2010 apparatus. Before the analysis, the samples were degassed at $200{ }^{\circ} \mathrm{C}$ overnight. Weight losses comprised between $8 \%$ (EC-500) and 13\% (E) are due to the removal of physisorbed water molecules (Elemental analyses of EC-200 before and after the $\mathrm{N}_{2}$ sorption measurements showed that the sample is stable under these conditions $(\mathrm{S} / \mathrm{Si}=0.1$ in both cases)). The specific surface areas $\left(S_{\mathrm{BET}}\right)$ were evaluated using the Brunauer-Emmett-Teller (BET) method in the $P / P_{0}$ range of $0.05-0.25$. The pore volume $\left(V_{\mathrm{BJH}}\right)$ was determined from the desorption branch of the $\mathrm{N}_{2}$ isotherms using the
Barrett-Joyner-Halenda (BJH) method. Elemental analyses were performed by ICPAES (CNRS Analysis Centre, Vernaison, France) and by energy dispersive X-ray spectroscopy (EDXS) using a JEOL-2010F HRTEM $200 \mathrm{kV}$ field-emission microscope equipped with a Si(Li) detector (LINK ISIS 300, Oxford Instruments at the National Institute of Chemistry, Ljubljana, Slovenia). Infrared spectra were recorded at room temperature with a Nicolet Magna 550 FTIR spectrometer. Prior to the experiments, the self-supported wafer of EC-200 $\left(2 \mathrm{~cm}^{2}, 5-10 \mathrm{mg}\right)$ was placed in a quartz infrared cell and carefully dehydrated by heating under a vacuum during $5 \mathrm{~h}\left(1.5^{\circ} \mathrm{C} \mathrm{min}^{-1}, 200^{\circ} \mathrm{C}\right.$, $\left.10^{-3} \mathrm{~Pa}\right)$. Further heating under a vacuum was performed in situ (from 200 to $450^{\circ} \mathrm{C}$ ) in order to study the sample stability. Thermal analyses (TG-DSC) of the different solids were performed on a SDT 2960 thermal analysis system (TA Instruments, Inc.). All the samples were dried before at $52 \pm 1{ }^{\circ} \mathrm{C}$ (weight loss during this step were comprised between 4 and 12\%). The measurements were carried out in a constant $100 \mathrm{~mL} \mathrm{~min}^{-1} \mathrm{~N}_{2}$ flow with a heating rate of $10^{\circ} \mathrm{C} \mathrm{min}^{-1}$. Solid-state MAS ${ }^{33} \mathrm{~S}$ NMR measurements were recorded at $21.2 \mathrm{~T}$ at the National High Magnetic Field Laboratory (NHMFL) in Florida. The spectra were referenced to carbon sulfide.

\subsection{Catalysis tests}

Samples (E and EC-200) were used as catalysts in the synthesis of 2,2-[bis-(5-methylfuryl)]propane (DMP) and the decomposition of cumene hydroperoxide (CHP). Their catalytic performances are compared with those of Nafion-H (Aldrich, 7-9 mesh), Al-SBA-15 (Si/Al = 14) [37] and $\mathrm{H}_{2} \mathrm{SO}_{4}$ (96\%, Carlo Erba). All the GC analyses were performed on a Delsi Nermag DN 200 gas chromatograph equipped with a SPB ${ }^{\mathrm{TM}}-5$ (Supelco) column and a FID detector. The products, i.e. DMP, phenol were identified by GC-MS on a Trace GC 2000 series (Thermofinnigan) coupled to a Trace MS mass spectrometer (EI) using the NIST 98 library.

\subsubsection{Synthesis of DMP}

Weighted amounts of 2-methylfuran (1.8 g, $0.022 \mathrm{~mol}$, Aldrich) and acetone $(3.2 \mathrm{~g}, 0.055 \mathrm{~mol}$, Prolabo) as well as $100 \mu \mathrm{L}$ of undecane (internal standard, Aldrich) were added to the solid catalysts (E, $8 \mathrm{mg}$; EC-200, $7 \mathrm{mg}$; Nafion-H, $9 \mathrm{mg}$; $\left.\mathrm{H}_{2} \mathrm{SO}_{4} 96 \%, 0.4 \mu \mathrm{L}\right)$ in a round-botton flask. The resulting reaction mixture was stirred for $24 \mathrm{~h}$ at $50{ }^{\circ} \mathrm{C}$. Finally, the solid was separated by centrifugation and the supernatant liquid analysed by GC.

\subsubsection{CHP decomposition}

A weighted amount of the catalyst (Nafion-H, $0.25 \mathrm{~g}$; E, 0.14-0.11 g; EC-200, $0.12 \mathrm{~g} ; \mathrm{H}_{2} \mathrm{SO}_{4}, 11 \mu \mathrm{L}$; Al-SBA-15, $0.22 \mathrm{~g})$ was added to an hexane $(5 \mathrm{~mL})$ solution of $\mathrm{CHP}(0.61 \mathrm{~g}$, $3.5 \times 10^{-3} \mathrm{~mol}, 88 \%$, Aldrich) and of the internal standard, decane $(200 \mu \mathrm{L}$, Fluka). The resulting mixture was stirred for $3-24 \mathrm{~h}$ at room temperature. Withdrawals of the supernatant $(0.5 \mathrm{~mL})$ were carried out at 3,6 and $24 \mathrm{~h}$. In order to stop the reaction, the aliquots were treated with $0.5 \mathrm{~mL}$ of a $0.35 \mathrm{M}$ triphenylphosphine solution in acetone and analysed by GC. 
Caution: The CHP decomposition is a strong exothermic reaction and it has to be noted that the reactants were added following strictly the order described in the above procedure.

\section{Results and discussion}

The pre-hydrolysis of TEOS is usually a prerequisite for the preparation of SBA-ar- $\mathrm{SO}_{3} \mathrm{H}$ by a co-condensation procedure. Depending on the reported syntheses, such step can be carried out either in the presence [19,24] or in the absence [21] of the surfactant (Pluronic P123) as long as the incorporation ratio R ((CSPTMS/(CSPTMS + TEOS)) is inferior to 0.1. Ratio upper than this value can lead to materials with a double porosity when TEOS is hydrolysed alone [21]. The present study is aiming at the preparation of solids with one pore dimension and more than $1 \mathrm{mmol} \mathrm{g}^{-1}$ of the sulphonic groups $(R>0.1)$ this is why the procedure used was adapted from the work of Wang et al. $[12,24]$.

\subsection{Surfactant removal}

The removal of the surfactant from the as-synthesised material was performed by refluxing the solid in ethanol for $24 \mathrm{~h}$. XRD data for sample $\mathrm{E}$ are in agreement with those reported by Wang et al. (Fig. 1). The half-width of the diffraction peak associated to the (1 100$)$ plane of the $P 6 \mathrm{~mm}$ structure (at $2 \theta=0.8^{\circ}$ ) is wider than the corresponding signal obtained for a pure SBA-15 silica. The smaller signals observed on the enlargement of the diffractogram account for the presence of some hexagonal order in agreement with the TEM pictures (not shown here).

The sulfur content and the relative carbon/sulfur molar ratio of the modified mesoporous silica are reported in Table 1 . The ethylarylsulfonic groups have been inserted to a lower extent than expected: elemental analyses of the sample $\mathrm{E}$ indicate that the value of the $\mathrm{S} / \mathrm{Si}$ ratio is 0.11 instead of 0.15 . It can be noted also that the mean value of the experimental molar $\mathrm{C} / \mathrm{S}$ ratio is 9.4 instead of 8 . Such difference can be attributed to the presence of residual amounts of Pluronic P123. This may also arise from non-hydrolysed methoxy groups from CSPTMS [29] or correspond to ethoxy groups which can be present as a result of alkoxy exchange between $\mathrm{MeO}-\mathrm{Si}$ and the $\mathrm{EtOH}$ used in the extraction step. The extraction procedure remains rather efficient. In this paper, we propose the use of a smooth calcination step $\left(200^{\circ} \mathrm{C}\right)$ in order to further reduce the excess of carbon without damaging the acidic functions.

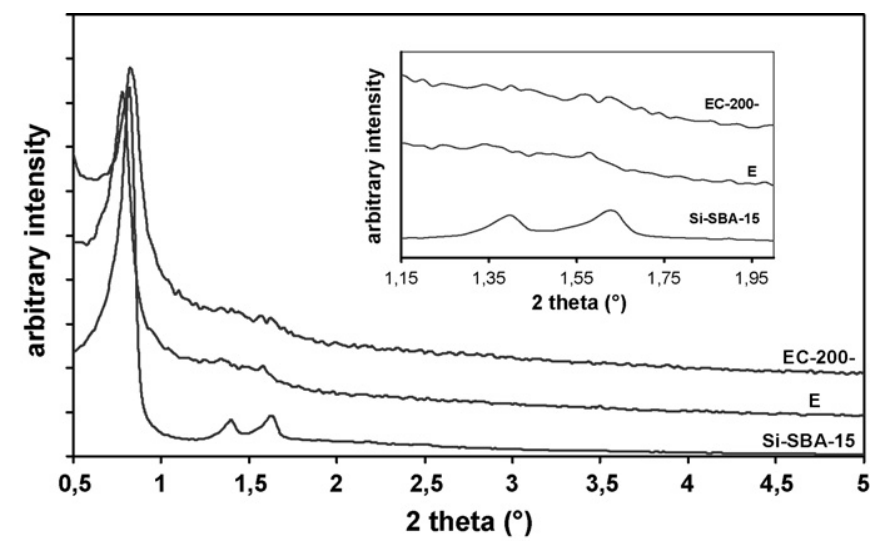

Fig. 1. Small angle X-ray powder diffraction patterns of Si-SBA-15, E and EC-200 samples.

The EC-200 solid resulting from the calcination of the extracted sample is characterised by little bit smaller values of its sulfur and carbon weight percentages than E (Table 1). It is like that some CSPTMS molecules of sample $\mathrm{E}$ were not tightly linked to the surface. They may have been removed during the additional step. The new C/S ratio is closer to 9 in accordance with the anchorage of the functional groups by two $\mathrm{Si}-\mathrm{O}-\mathrm{Si}$ linkages instead of three. Benefits of the smooth calcination step appear from the significant increase of the different textural parameters. Values of the mean pore diameter and of the specific surface area of the extracted sample are in the range of those reported in the literature $[11,12]$.

Both nitrogen sorption curves of the sulfonic solids (E and EC-200) are type IV isotherms consistent with mesoporous materials tailored by Pluronic P123 (Fig. 2). However, the increase of the amount of adsorbed gas at $P / P_{0} 0.65-0.75$ is not as steep as in the pure silica sample. Hystereses of the hybrid samples are wider and stretched but they still remain of type $\mathrm{H} 1$. Such observation is in agreement with the less ordered structure of these solids as evidenced by XRD data (Fig. 1). A second smaller hysteresis is present for $P / P_{0}$ values around 0.45 . The nitrogen adsorption-desorption isotherms of E and EC-200 samples are very similar within a translation. On the assumption that the organic groups are homogeneously distributed, the "coverage" of the surface could be estimated to 1.65 and $1.3 \mu \mathrm{mol}$ of sulfur $\mathrm{m}^{-2}$ in E and EC-200, respectively (Table 1). The variation is mainly attributed to the increase of the surface area upon calcination since the sulfur and carbon wt.\% are almost unchanged. The treatment at $200{ }^{\circ} \mathrm{C}$ has no noticeable effect on

Table 1

Physicochemical and textural properties of the E and EC-T samples

\begin{tabular}{|c|c|c|c|c|c|c|c|c|}
\hline \multirow[t]{2}{*}{ Sample } & \multirow[t]{2}{*}{$S_{\text {BET }}\left(\mathrm{m}^{2} \mathrm{~g}^{-1}\right)$} & \multirow[t]{2}{*}{$V_{\mathrm{BJH}}\left(\mathrm{cm}^{3} \mathrm{~g}^{-1}\right)$} & \multirow[t]{2}{*}{$D_{\mathrm{p}}(\mathrm{nm})$} & \multicolumn{3}{|c|}{ Elemental analysis (\%) } & \multirow[t]{2}{*}{$\mathrm{C} / \mathrm{S}$} & \multirow[t]{2}{*}{$\mathrm{SO}_{3} \mathrm{H}^{\mathrm{a}}$} \\
\hline & & & & $\mathrm{Si}$ & $\mathrm{C}$ & $\mathrm{S}$ & & \\
\hline $\mathrm{E}$ & 600 & 0.42 & 6.6 & 27.4 & 11.1 & 3.2 & 9.4 & $9.9 \times 10^{-4}\left(1.65 \times 10^{-6}\right)$ \\
\hline EC-200 & 710 & 0.47 & 6.9 & 28.9 & 10.2 & 3.0 & 9.0 & $9.4 \times 10^{-4}\left(1.3 \times 10^{-6}\right)$ \\
\hline EC-400 & 720 & 0.52 & 7.0 & 28.3 & 11.0 & 2.5 & 10.4 & $8.0 \times^{-4}\left(1.1 \times 10^{-6}\right)$ \\
\hline EC-500 & 860 & 0.62 & 6.8 & 37.3 & 1.45 & 0.3 & 13.0 & $9.4 \times 10^{-5}\left(0.1 \times 10^{-6}\right)$ \\
\hline
\end{tabular}

a Sulfur content as mol of $\mathrm{S} \mathrm{g}^{-1}$ of $\mathrm{SiO}_{2}$ calculated from the elemental analyses. An estimation of the "coverage" of the surface $\left(\mathrm{mol}^{\text {of }} \mathrm{S} \mathrm{m}{ }^{-2}\right)$ is indicated between the parentheses. 


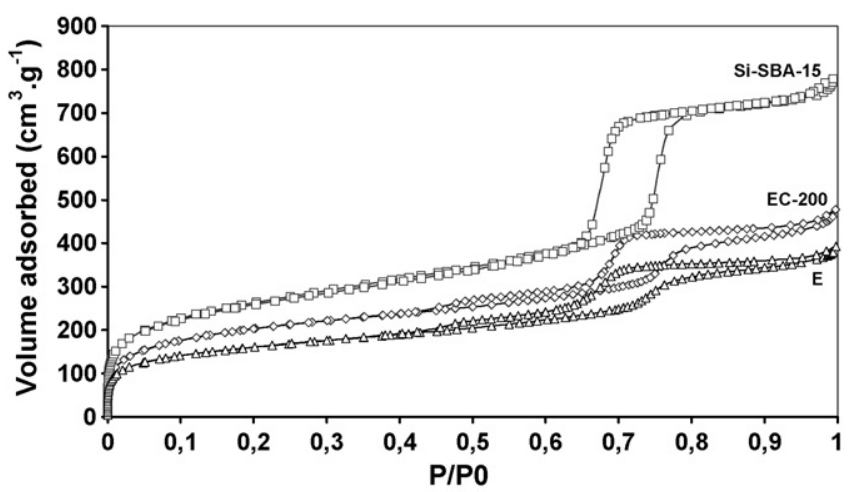

Fig. 2. Nitrogen adsorption-desorption isotherms of Si-SBA-15, E and EC-200 samples.

the aspect of the XRD diagram (Fig. 1). There is only a slight shift of the $\left(\begin{array}{lll}1 & 0 & 0\end{array}\right)$ diffraction peak toward higher $2 \theta$ values. In other words, the lattice contracts with the calcination treatment.

Such hybrid solids are usually characterised by MAS ${ }^{29} \mathrm{Si}$ [8,10,13-15,24,29] and ${ }^{13}$ C NMR [8,10,13-15,19,24,25,29,31]. To our knowledge, no ${ }^{33} \mathrm{~S}$ NMR measurements were actually performed on such materials. ${ }^{33} \mathrm{~S}$ is a quadrupolar nucleus $(I=3 / 2)$ with a low gyromagnetic ratio $\left(2.052 .10^{7} \mathrm{rad} / \mathrm{T}\right)$ and low natural abundance $(0.76 \%)$. That is probably why ${ }^{33} \mathrm{~S} N M R$ has so far not been widely used in the chemistry of materials. In the present paper, ${ }^{33} \mathrm{~S} N M R$ data have been collected for the EC200 solid (Fig. 3) in order to emphasise the presence of the sole sulfonic groups. Indeed, the resulting spectrum displays only one peak $(\delta=320 \mathrm{ppm})$ which can be attributed to sulfur in its highest oxidation number. In this aspect, CSPTMS is a better precursor than thiols whose oxidation is known to be difficult.

\subsection{Infrared characterisation of EC-200}

\subsubsection{Evidences for the presence of the $\mathrm{SO}_{3} \mathrm{H}$ function}

The sulfonic acid groups can be evidenced from their interaction with ammonia using infrared spectroscopy (Fig. 4). Indeed,

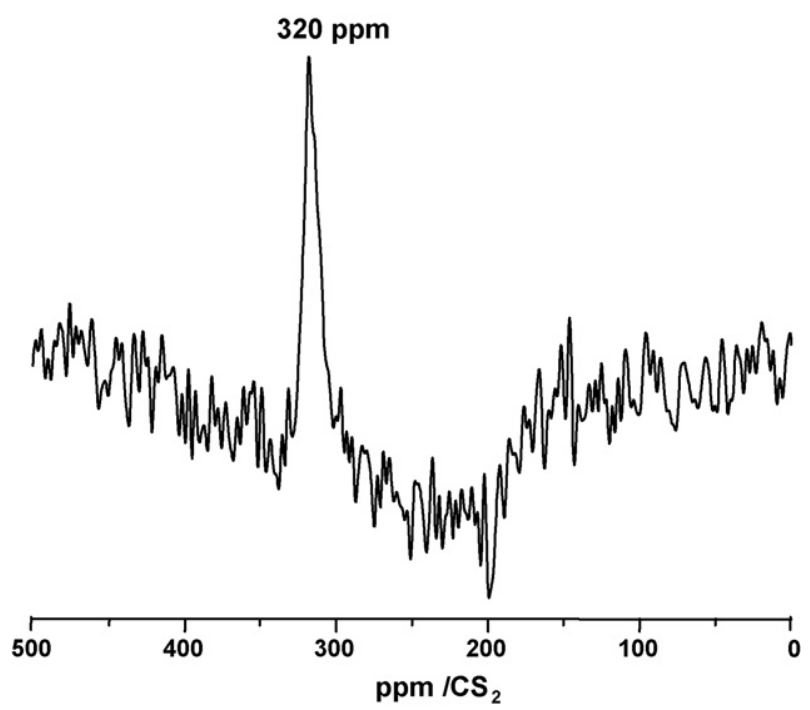

Fig. 3. ${ }^{33}$ S NMR spectrum of EC-200.

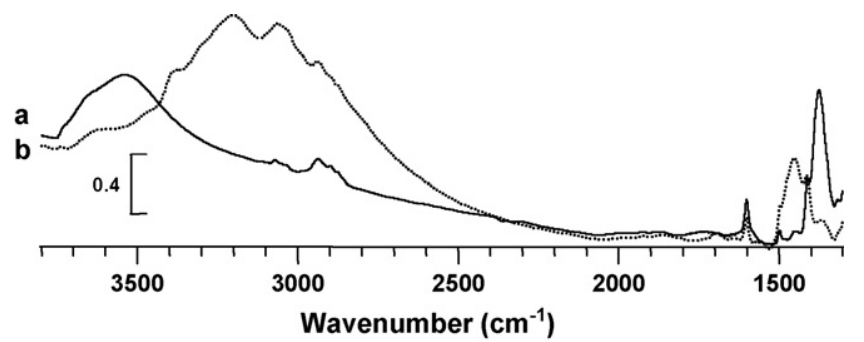

Fig. 4. Infrared spectra in the $3800-1300 \mathrm{~cm}^{-1}$ region for EC-200 pretreated at $200{ }^{\circ} \mathrm{C}$ (a) and after the adsorption of $\mathrm{NH}_{3}$ at $150{ }^{\circ} \mathrm{C}$ (1 Torr at equilibrium (b)).

the comparison of the spectra of EC-200 before and after the adsorption of $\mathrm{NH}_{3}$ (1 Torr at equilibrium) points out the appearance of the band corresponding to the $\delta(\mathrm{NH})$ bending mode of $\mathrm{NH}_{4}{ }^{+}$at $1454 \mathrm{~cm}^{-1}$. Such a band can be considered as a proof of a direct interaction between $\mathrm{NH}_{3}$ and the $\mathrm{SO}_{3} \mathrm{H}$ groups given that it is not present in the case of pure SBA-15 silica (not shown here). The $v(\mathrm{SO})$ stretch vibration of the $\mathrm{SO}_{3} \mathrm{H}$ group around $1373 \mathrm{~cm}^{-1}$ [29] is quantitatively affected till its complete disappearance. Actually, the band corresponding to $v(\mathrm{SO})$ of the $\mathrm{SO}_{3}{ }^{-}$ group which is formed is strongly shifted downwards and cannot be observed due to the strong absorbance of the $\mathrm{Si}-\mathrm{O}$ vibrations. The comparison of the spectra in the $2800-3400 \mathrm{~cm}^{-1}$ window is rather complicated due to the introduction of ammonia. Indeed, the rather strong base simultaneously interacts by hydrogen bonding with the hydroxyl groups of silanols and with the $\mathrm{SO}_{3} \mathrm{H}$ function (expected between 2500 and $3500 \mathrm{~cm}^{-1}$ $[24,29])$ giving rise to new absorption bands corresponding to the $v(\mathrm{NH})$ vibrations of $\mathrm{NH}_{4}{ }^{+}$species from 3245 to $2815 \mathrm{~cm}^{-1}$. The proton transfer from the sulfonic SBA-15 samples to the $\mathrm{NH}_{3}$ molecule is reversible starting from $150{ }^{\circ} \mathrm{C}$ since during $\mathrm{NH}_{3}$ TPD followed by IR, this temperature corresponds to the one at which the $\delta(\mathrm{NH})$ typical of $\mathrm{NH}_{4}{ }^{+}$disappear and $v(\mathrm{SO})$ typical of $\mathrm{SO}_{3} \mathrm{H}$ groups reappear, the complete removal of $\mathrm{NH}_{4}{ }^{+}$species being reached at $200{ }^{\circ} \mathrm{C}$ (not shown here).

\subsubsection{Thermal stability of EC-200}

One of the main applications of acid functionalised mesoporous samples is heterogeneous catalysis which often requires rather high reaction temperature. We thus decided to study the thermal stability of the arenesulfonic groups using the EC-200 sample.

The Fig. 5 represents the FTIR spectra of EC-200 over a wide infrared region as a function of the pre-treatment temperature $\left(200-450^{\circ} \mathrm{C}\right)$.

Based on literature data regarding infrared spectroscopic features assigned to silanols stretching vibrations [38,39], we were able to interpret our data. For the softer thermal treatment $\left(200^{\circ} \mathrm{C}\right.$, Fig. 5a), dehydroxylation of the surface very little occurs and pairs of silanols are still present giving rise to a wide $\nu\left(\mathrm{OH}\right.$. . ) band around $3540 \mathrm{~cm}^{-1}$ (Fig. 6a). The associated $v(-\mathrm{OH})$ component at $3715 \mathrm{~cm}^{-1}$ is apparently hidden by the high wavenumber tail of the wide hydroxyl infrared multi-component band. A second rather wide component is present around $3660 \mathrm{~cm}^{-1}$ and remains almost constant with increasing temperature. This is consistent with an attribution to 


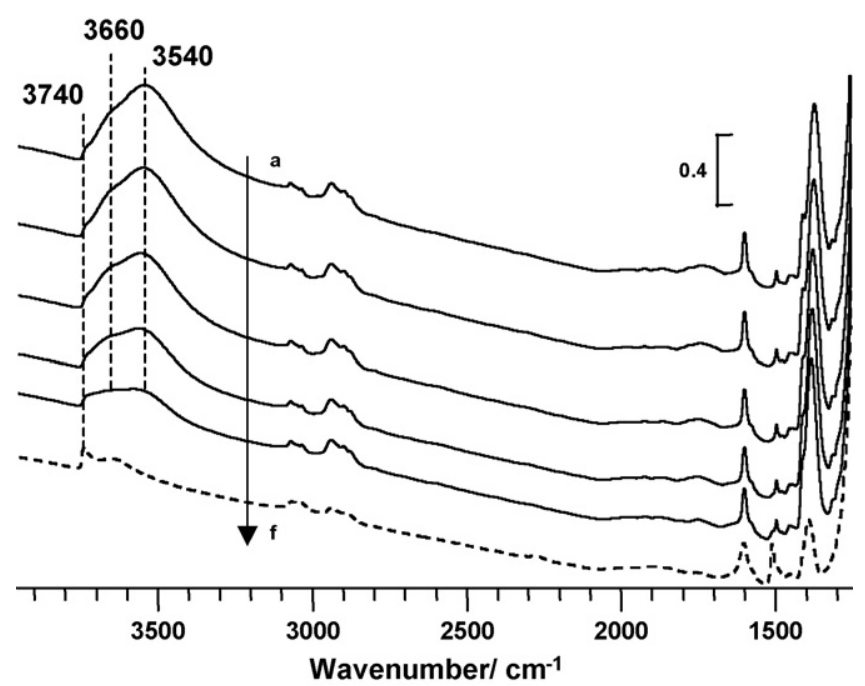

Fig. 5. Infrared spectra in the $3800-1300 \mathrm{~cm}^{-1}$ region for EC-200 after increasing temperature under a vacuum. (a) $200^{\circ} \mathrm{C}$, (b) $250^{\circ} \mathrm{C}$, (c) $300^{\circ} \mathrm{C}$, (d) $350^{\circ} \mathrm{C}$, (e) $400{ }^{\circ} \mathrm{C}$, (f) $450{ }^{\circ} \mathrm{C}$.

internal silanol groups (Fig. 6b) which are quite difficult to dehydroxylate. However H-bonding interaction with another type of tethered functional group $\left(-\mathrm{SO}_{3} \mathrm{H}\right.$ for example) may also lead to this $3660 \mathrm{~cm}^{-1}$ shoulder. Finally, isolated silanols (single or geminated) are characterised by the band around $3740 \mathrm{~cm}^{-1}$ (Fig. 6c) whose intensity mainly increases from $400^{\circ} \mathrm{C}$, i.e. when the arylsulfonic groups start to decompose leaving isolated $\mathrm{Si}-\mathrm{OH}$ on the silica surface.

More information are obtained about the thermal stability of the $\mathrm{Si}_{-} \mathrm{C}_{2} \mathrm{H}_{4}$-phenyl- $\mathrm{SO}_{3} \mathrm{H}$ groups by focusing on the $v(\mathrm{CH})$ stretching vibration region (Fig. 7). From 200 to $300^{\circ} \mathrm{C}$ (Fig. 7a-c), almost no change is observed in the aromatic $v(\mathrm{CH})$ vibrations (3071 and $3036 \mathrm{~cm}^{-1}$ ) or in the ethyl $v\left(\mathrm{CH}_{2}\right)$ vibrations $\left(2939-2879 \mathrm{~cm}^{-1}\right.$ [10]) both from the position and the intensity point of view. However, some thermal decomposition occurs between 400 and $450^{\circ} \mathrm{C}$ (Fig. 7e and f) as indicated by the relative decrease of the ethyl group $v\left(\mathrm{CH}_{2}\right)$ component. Moreover, the aromatic $v(\mathrm{CH})$ massif becomes wider and less resolved at $400^{\circ} \mathrm{C}$ (Fig. 7e) in agreement with a larger distribution of the $v(\mathrm{CH})$ vibrations due to the possible formation of new aromatic species.

These interpretations are confirmed by the analysis of the $1700-1300 \mathrm{~cm}^{-1}$ zone (Fig. 8). Indeed, the bending mode of the $\left(\mathrm{CH}_{2}\right)$ groups at $1410 \mathrm{~cm}^{-1}[10,15,29]$ has nearly disappeared at $450{ }^{\circ} \mathrm{C}$ (Fig. 8f). The $v(\mathrm{C}=\mathrm{C})$ vibration typical of aromatic

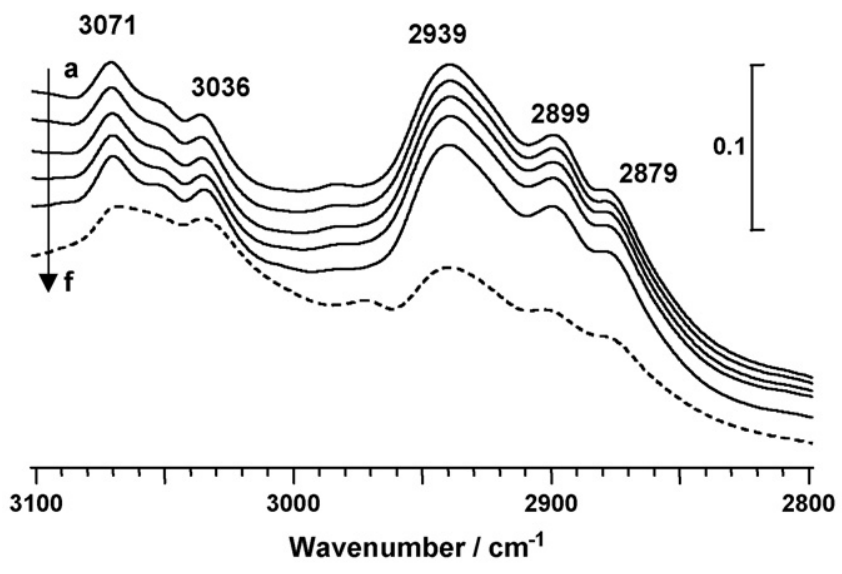

Fig. 7. $v(\mathrm{CH})$ stretching vibrations for $\mathrm{EC}-200$ after increasing temperature under a vacuum. (a) $200^{\circ} \mathrm{C}$, (b) $250^{\circ} \mathrm{C}$, (c) $300^{\circ} \mathrm{C}$, (d) $350^{\circ} \mathrm{C}$, (e) $400^{\circ} \mathrm{C}$, (f) $450^{\circ} \mathrm{C}$.

cycle at $1600 \mathrm{~cm}^{-1}[15]$ becomes wider at this temperature and a new component at $1510 \mathrm{~cm}^{-1}$ confirms the formation of new aromatic species. Finally, the $v(\mathrm{~S}=\mathrm{O})$ component characteristic of the sulfonic acid, slighty shifts from 1373 to $1392 \mathrm{~cm}^{-1}$ when the temperature increases. The $v(\mathrm{~S}=\mathrm{O})$ band intensity very little changes until $400^{\circ} \mathrm{C}$ (Fig. 8a-e) and in this case the upwards shift is probably due to the progressive elimination of silanols pairs which were previously weakly interacting with



Fig. 8. Infrared spectra in the $1700-1270 \mathrm{~cm}^{-1}$ region for EC-200 after increasing temperature under a vacuum. (a) $200^{\circ} \mathrm{C}$, (b) $250{ }^{\circ} \mathrm{C}$, (c) $300^{\circ} \mathrm{C}$, (d) $350^{\circ} \mathrm{C}$, (e) $400^{\circ} \mathrm{C}$, (f) $450{ }^{\circ} \mathrm{C}$.

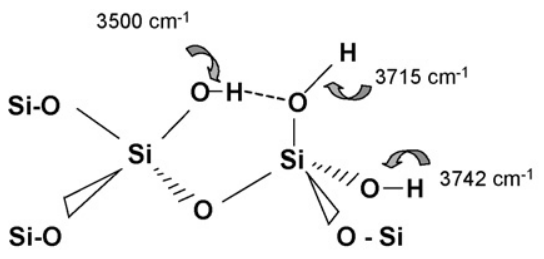

(a)

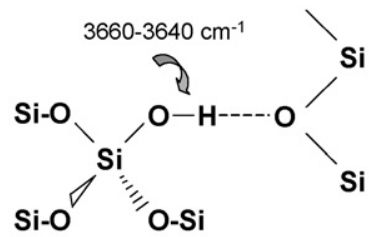

(b)

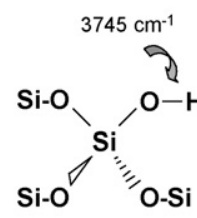

(c)

Fig. 6. (a) Silanols pair in hydrogen bonding (one of the interacting hydroxyl being part of a geminal silanol) [from Ref. [40]]. (b) Internal silanol whose hydroxyl interacts by hydrogen bonding with neighbouring siloxane group [from Ref. [41]]. (c) Isolated single silanol (left) and isolated geminated silanol (right). 
$\mathrm{SO}_{3} \mathrm{H}$ groups. Finally, at $450^{\circ} \mathrm{C}(\mathrm{Fig}$. 8e) the $v(\mathrm{~S}=\mathrm{O})$ band intensity has considerably decreased but a component still remain at $1392 \mathrm{~cm}^{-1}$ which implies the non complete destruction of the sulfonic groups at such a high temperature.

The ethylarylsulfonic groups of EC-200 samples present a rather good thermal stability until $400{ }^{\circ} \mathrm{C}$ since the main change observed on the surface is related to water elimination resulting from silanol pairs dehydroxylation. Such conclusion lead us to prepare and study the materials EC-400 and EC-500 obtained by the calcination of $\mathrm{E}$ at 400 and even $500^{\circ} \mathrm{C}$, respectively. The textural and physicochemical properties of both samples are reported in Table 1. Elemental analyses of EC-400 show that $0.8 \mathrm{mmol}$ of sulfur atom $\mathrm{g}^{-1}$ of materials is still present whereas there is only $0.09 \mathrm{mmol} \mathrm{g}^{-1}$ in the case of EC-500. The increase in the calcination temperature results in a shift of the specific surface area and of the porous volume toward higher values $\left(860 \mathrm{~m}^{2} \mathrm{~g}^{-1}, 0.62 \mathrm{~cm}^{3} \mathrm{~g}^{-1}\right.$, respectively). The main variations are observed between 400 and $500{ }^{\circ} \mathrm{C}$ in agreement with the infrared and elemental analysis data. It turns out that the addition of CSPTMS in the synthesis gel has a strong impact on the porous volume of the material. Indeed, once the organic part is calcined (EC-500), Vp is still lower by $40 \%$ than expected for a pure silica SBA-15 sample [42]. On the contrary, the values of the specific surface area and porous diameter of EC-500 are very close to those of Si-SBA-15.

All the solids have been dried at $52{ }^{\circ} \mathrm{C}$ and analysed by TG-DSC between 52 and $900^{\circ} \mathrm{C}$ (Fig. 9). The weight loss during the preliminary drying treatment corresponds to the
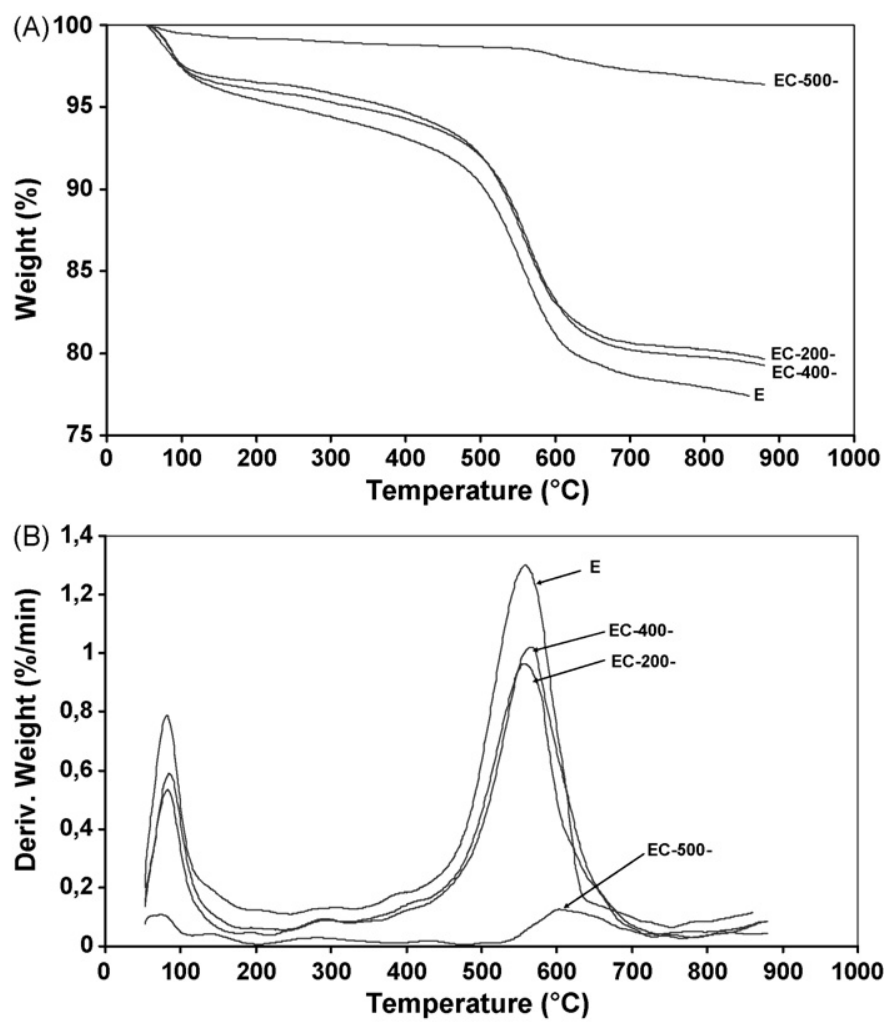

Fig. 9. Representative thermogravimetric weight loss curves (a) and derivative plots (b) for E and EC-T samples. removal of physisorbed water. It decreases from 11.5 to $6.0 \%$ in agreement with the expected reduction of the number of available silanol groups upon the increase of the calcination temperature.

The rather good thermal stability of the organic group until $400^{\circ} \mathrm{C}$ is supported by the similarities between the thermogravimetric weight loss curves of E, EC-200 and EC-400. The most important total weight loss between 52 and $900^{\circ} \mathrm{C}$ is observed in the case of sample E (22.5\%). Those of EC-200 and EC-400 are not very different (19.5 and 20\%, respectively). The derivative plots of these curves (Fig. 9b) are characterised by two main peaks at $82-85$ and $557-565^{\circ} \mathrm{C}$ which can be attributed to the removal of the physically adsorbed water or ethanol $[13,15,31]$ and the thermal decomposition of the aromatic functional group $[11,16,17,19]$. The second peak seems to be shifted to higher values upon the increase of the calcination temperature. Other minor losses centred at $150,275,400$ and $650^{\circ} \mathrm{C}$ are observed in all the samples. Diffuse weight losses between 150 and $450^{\circ} \mathrm{C}$ are more important in the E sample compared to EC-200. This difference arises probably from the presence of some Pluronic P123 in the first material [11]. The EC-500 sample is different with only $3.5 \%$ of total weight loss between 52 and $900{ }^{\circ} \mathrm{C}$. In this last case, the slight and continuous weight decrease through the $400-900^{\circ} \mathrm{C}$ range is probably due to the desorption of water resulting from the condensation of silanol groups [30,35].

The main application of such arenesulfonic functionalised materials is their use as alternative to acid catalysts. Two organic transformations previously not tested with $\mathrm{SBA}-\mathrm{SO}_{3} \mathrm{H}$ materials were selected in order to look at the influence of the $200^{\circ} \mathrm{C}$ calcination step on their catalytic activity.

\subsection{Catalysis tests}

\subsubsection{Acid-catalysed condensation of acetone and 2-methylfuran}

The Friedel-Crafts type reaction of acetone and 2methylfuran (Scheme 1) envisaged here is a model for the preparation of different gem-difurylalkanes [43]. First versions of an heterogeneous liquid phase catalytic system have been reported by Algarra et al. using tridirectional large pore zeolites $\mathrm{Y}$ and $\beta$ [43]. A total conversion with complete selectivity of the gem-difurylalkane and thus a strong decrease of the 2-alkylfuran oligomerisation was obtained with elevated catalyst concentrations. More recently, Van Rhijn et al. [25] and Li et al. [44] have shown that lower amounts of MCM-41 type materials bearing either propylsulfonic groups or $\mathrm{MoO}_{3} / \mathrm{ZrO}_{2}$ are excellent catalysts for the formation of bisfurylalkanes. Both research groups got a $80 \%$ yield of 2,2-[bis-(5-methylfuryl)]propane (DMP) by working with a $2.5: 1$ acetone:MF molar ratio at $50{ }^{\circ} \mathrm{C}$ for

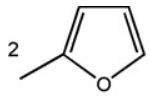

MF

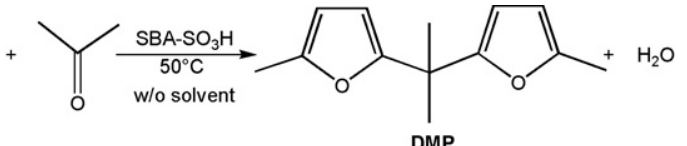

DMP
Scheme 1 
Table 2

Conversion and selectivities in the condensation of 2-methylfuran and acetone $($ reaction time $=24 \mathrm{~h})$

\begin{tabular}{llll}
\hline Material & MF/H $/ \mathrm{H}^{+}$(mole) & MF conv. (\%) & DMP yield (\%) \\
\hline & & $86(1 \mathrm{st})$ & 78 \\
$\mathrm{E}$ & 2800 & $84.5(2 \mathrm{nd})$ & 79 \\
& & $72.5(3 \mathrm{rd})$ & 64 \\
& $67(4 \mathrm{th})$ & 60 \\
EC-200 & 3350 & 65 & 60 \\
$\mathrm{Nafion}^{\circledR} \mathrm{NR} \mathrm{50}$ & 3050 & 28 & 22 \\
$\mathrm{H}_{2} \mathrm{SO}_{4}(96 \%)$ & 2970 & 13 & 10 \\
\hline
\end{tabular}

$24 \mathrm{~h}$. High DMP selectivities were attributed to the juxtaposition of the low MF adsorption on the relatively hydrophobic surface of $\mathrm{MCM}-\mathrm{SO}_{3} \mathrm{H}$ and of the easy desorption of the products from the catalytic sites within the MCM-41 mesopores. Our study presents the first use of SBA- 15 type materials as catalysts for the conversion of MF to DMP. The amounts of acetone and MF are strictly comparable to those used previously. However the values of the substrate $/ \mathrm{H}^{+}$ratio tested are roughly 30 times lower than those used by Van Rhijn et al. and $\mathrm{Li}$ et al. [25,44]. The results of the tests performed with $\mathrm{E}$ and EC-200 as well as Nafion- $\mathrm{H}$ or $\mathrm{H}_{2} \mathrm{SO}_{4}$ are summarised in Table 2.

We confirm here that there is no MF consumption and DMP formation in the absence of any proton source [25,44]. The highest yields of the gem-difurylalkane are obtained in the presence of SBA-SO ${ }_{3} \mathrm{H}$ despite the relatively high substrate $/ \mathrm{H}^{+}$ ratio $(\approx 3000)$ used. Sulfuric acid is much less active and selective for the transformation of MF to DMP as indicated before by Algarra et al. [43]. Nafion-H (NR50) exhibit poor catalytic performances. The mass balance is quite low and mirrors the involvement of side polymerisation processes inherent to diffusion limitations. It has to be noticed that perfluorinated sulfonic acids immobilised into mesoporous silica frameworks [45] work much better than the NR50 resins affording yields of DMP similar to MCM-41 $\mathrm{SO}_{3} \mathrm{H}$ and $\mathrm{MoO}_{3} / \mathrm{ZrO}_{2} / \mathrm{MCM}-41$. Samples E and EC-200 are also leading to better conversion rates and DMP selectivity (90\%) than Nafion-H beads. Furthermore turn over numbers in the range of $1000 \mathrm{~mol}$ of product $/ \mathrm{mol}$ of active site are obtained in the presence of the arenesulfonic modified SBA-15 solids. The extracted SBA-15 type catalyst modified with ethylarylsulfonic groups (E) appears to be slightly more active than the MCM-41 solids functionalised with propylsulfonic groups [25]. The deactivation behavior of $\mathrm{E}$ was examined by recycling the recovered dried solid in three other successive runs. The results of the two first tests are very similar; others show some decrease in the activity but the selectivity still remains as high as $90 \%$. The preliminary calcination treatment of $\mathrm{E}$ has no effect on the selectivity of the acid-catalysed process but the activity of the solid is reduced.

\subsubsection{Acid-catalysed decomposition of cumene hydroperoxide}

Materials doted with arenesulfonic groups are usually presented as green alternatives to sulfuric acid and are thus

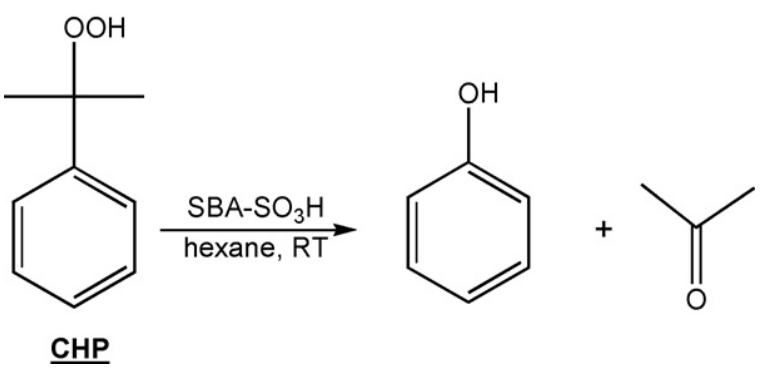

Scheme 2.

tested in reactions usually performed under homogeneous conditions in the presence of this diacid (esterification $[8,13,15,18,23,25,26,30,35,36]$, Beckmann rearrangement $[12,22])$. Surprisingly, no use of sulfonic acid-functionalised mesoporous silica has been reported for the decomposition of cumene hydroperoxide (CHP) into phenol and acetone (Scheme 2) despite the commercial importance of this process. However, it remains of great interest and significance to develop a non-polluting liquid/solid catalysis system for the phenol preparation. Solid acids like clays, zeolites and resins have been studied extensively [46-48].

In the present work, we report, for the first time, on reactions that have been carried out in hexane at room temperature using E or EC-200 samples as well as acid references like NR 50 (Nafion-H), Al-SBA-15 and $\mathrm{H}_{2} \mathrm{SO}_{4}$ (Table 3). For the sake of comparison, the amounts of all the acid sources are such that the molar substrate $/ \mathrm{H}^{+}$ratio is comprised between 20 and 30 (see Section 2).

Three types of materials can be distinguished on the behalf of the evolution of the conversion versus time. The fastest reaction is the one carried under homogeneous conditions in the presence of $\mathrm{H}_{2} \mathrm{SO}_{4}$ ( $t_{1 / 2}$ (half-life time) of CHP less than $2 \mathrm{~h}$ ). The slowest being the decomposition of CHP with Al-SBA- $15\left(t_{1 / 2} \approx 12 \mathrm{~h}\right)$. Strong acid sites are required in order to improve the catalysts performances. As a matter of fact, all the sulfonic materials, i.e. SBA-SO $3 \mathrm{H}\left(3 \mathrm{~h}<t_{1 / 2}<6 \mathrm{~h}\right)$ and NR 50 solids $\left(t_{1 / 2} \approx 3 \mathrm{~h}\right)$ are more active. Excepted for the Al-SBA-15 solid, the final mass balances are close to $100 \%$. Phenol is the only product detected (CHP conversion $\approx$ phenol yield). The differences between the conversion and yields for intermediate times are apparently due to the slow desorption of phenol from the catalyst. It is clear from the comparison of the results obtained with the samples $\mathrm{E}\left(t_{1 / 2}<6 \mathrm{~h}\right)$ and EC-200 $\left(t_{1 / 2} \approx 3 \mathrm{~h}\right)$ that the supplementary calcination treatment has beneficial effects on the kinetics of the phenol release into the solution. It is noteworthy that the curves of the conversion versus time are superimposed for EC-200 (1st test) and the Nafion-H materials. Such similarities may be due to an increase in the hydrophobicity of the surface [13].

Further, the stability of E and EC-200 samples was also assessed. After the first run, the catalysts were filtered off, repeatedly washed, dried and recycled under the same conditions. Little deactivation of E and EC-200 is observed during the second run. The EC-200 catalyst still allows an easier release of the phenol compared to $\mathrm{E}$. 
Table 3

Conversion and selectivities in the CHP decomposition

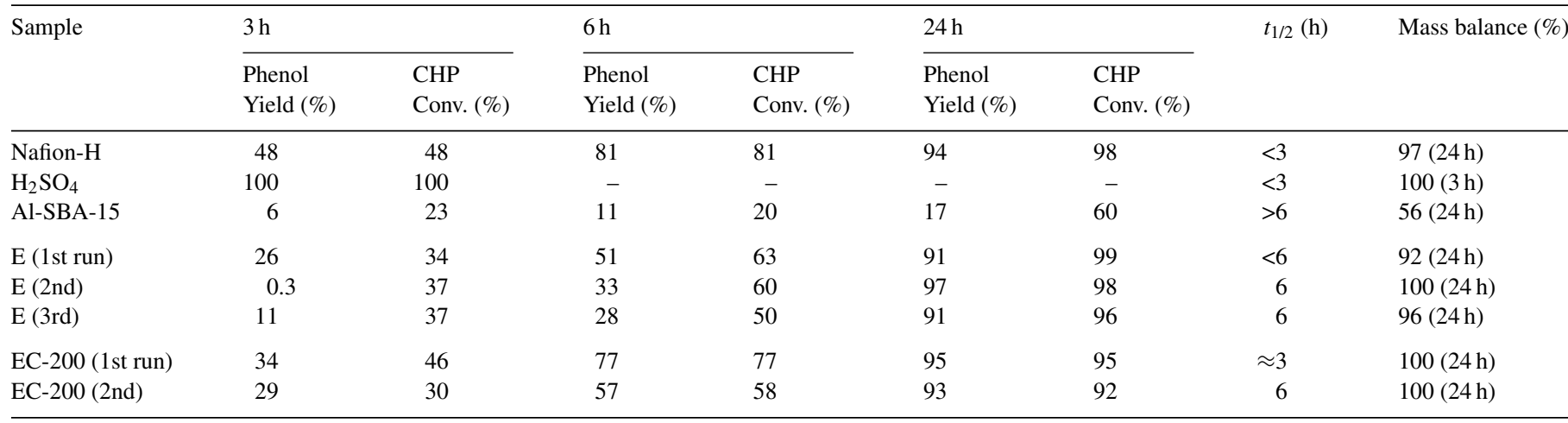

\section{Conclusion}

An arenesulfonic modified SBA-15 material with $3 \mathrm{wt} . \%$ of sulfur was prepared via the co-condensation technique using 2-(4-chlorosulfonylphenyl)ethyltrimethoxysilane (CSPTMS) in the presence of Pluronic P123. The thermogravimetric analysis (TGA) of the material recovered from the ethanol extraction (E) confirmed the thermal stability of the arenesulfonic group. Based on these results, a smooth calcination treatment of $E$ was performed at $200^{\circ} \mathrm{C}$ under air $(6 \mathrm{~h})$ in order to optimise the removal of the surfactant and possibly the organic groups not tightly bounded to the surface. The preservation of the organic function in the resulting solid (EC-200) was assessed by MAS ${ }^{33}$ S NMR, elemental analyses, TGA and FTIR spectroscopy.

The qualitative FTIR analysis of this kind of arenesulfonic material (EC-200) versus temperature was performed for the first time. It clearly showed that the sulfonic groups are not damaged to a great extent before $400^{\circ} \mathrm{C}$ and hence completes the quantitative data obtained by the TGA measurements. Actually, the elemental analyses of the samples calcined at $400^{\circ} \mathrm{C}$ (EC400 ) and $500{ }^{\circ} \mathrm{C}$ (EC-500) indicated that $80 \%$ of the initial sulfur loading was still present in EC-400 whereas it is about less than $10 \%$ in EC-500.

Both E and EC-200 samples have been tested successfully in two acid-catalysed processes: (i) a reference reaction, the condensation of acetone and 2-methylfuran and (ii) a reaction of industrial importance, the conversion of cumene hydroperoxide into phenol. The new E and EC-200 catalysts led to better yields of DMP than the Nafion-H commercial resins. Moreover, the performances of the $\mathrm{E}$ sample were very close to those of acidic MCM-41 derivatives previously reported. This clearly showed that further increase of the pore diameter has no effect on the formation of DMP. The $\mathrm{SBA}-\mathrm{SO}_{3} \mathrm{H}$ (E) solid turned out to be reasonably active over four successive tests (DMP yields: 78-60\%) and exhibited turnover numbers as high as 1000 mol of product per mol of $\mathrm{H}^{+}$. The E-sample appeared to be a more efficient catalyst than EC-200 but the effect of the smooth calcination treatment cannot be generalized. Indeed, the decomposition of CHP turned out to be faster over EC-200 than E. In this latter case, the activity of EC-200 is similar to that of Nafion-H.

Finally, it should be noted that the thermal stability of the sulfonic acid-functionalised mesoporous SBA-15 silica should provide a better processing latitude than that of Nafion- $\mathrm{H}$ for catalytic applications.

\section{Acknowledgments}

The authors gratefully acknowledge Dr. Jean-Baptiste d'Espinose de la Caillerie for his help in collecting the MAS ${ }^{33}$ S NMR spectrum of the EC-200 sample.

\section{References}

[1] F.S. Xiao, Top. Catal. 35 (2005) 9.

[2] A. Taguchi, F. Schüth, Microporous Mesoporous Mater. 77 (2005) 1.

[3] A. Corma, Chem. Rev. 97 (1997) 2373.

[4] S. Habib, F. Launay, M.-A. Springuel-Huet, F. Guenneau, V. SemmerHerlédan, N. Novak Tušar, V. Kaučic, A. Gédéon, New J. Chem. 30 (2006) 1163.

[5] T.O. Do, S. Kaliaguine, Ser. Chem. Eng. 4 (2004) 47.

[6] M. Hartmann, Angew. Chem. Int. Ed. 43 (2004) 5880, and references therein.

[7] A.A. Campos, L. Martins, L.L. Oliveira, C.R. Silva, M. Wallau, E. Urquieta Gonzalez, Catal. Today 759 (2005) 107.

[8] I. Díaz, F. Mohino, T. Blasco, E. Sastre, J. Pérez-Pariente, Microporous Mesoporous Mater. 80 (2005) 33.

[9] J.M. Yang, J. Lü, Chin. J. Chem. 23 (2005) 349

[10] B. Rác, Á. Molnár, P. Forgo, M. Mohai, I. Bertóti, J. Mol. Catal. A: Chem. 244 (2006) 46.

[11] I.K. Mbaraka, B.H. Shanks, J. Catal. 244 (2006) 78.

[12] X. Wang, C.-C. Chen, S.-Y. Chen, Y. Mou, S. Cheng, Appl. Catal. A: Gen. 281 (2005) 47.

[13] Q. Yang, M.P. Kapoor, N. Shirokura, M. Ohashi, S. Inagaki, J.N. Kondo, K. Domen, J. Mater. Chem. 15 (2005) 666.

[14] L.M. Yang, Y.J. Wang, G.S. Luo, Y.Y. Dai, Microporous Mesoporous Mater. 84 (2005) 275.

[15] J. Liu, Q. Yang, M.P. Kapoor, N. Setoyama, S. Inagaki, J. Yang, L. Zhang, J. Phys. Chem. B 109 (2005) 12250.

[16] R. Van Grieken, J.A. Melero, G. Morales, Appl. Catal. A:Chem. 289 (2005) 143.

[17] S. Hamoudi, S. Royer, S. Kaliaguine, Microporous Mesoporous Mater. 71 (2004) 17.

[18] I.K. Mbaraka, D.R. Radu, V.S.Y. Lin, B.H. Shanks, J. Catal. 219 (2003) 329.

[19] J.A. Melero, G.D. Stucky, R. van Grieken, G. Morales, J. Mater. Chem. 12 (2002) 1664

[20] F. Guenneau, M. Nader, P. Salame, F. Launay, V. Semmer-Herlédan, A. Gédéon, Catal. Today 113 (2006) 126.

[21] V. Semmer-Herlédan, S. Dakhlaoui, F. Guenneau, E. Haddad, A. Gédéon, Stud. Surf. Sci. Catal. 154 (2004) 1519. 
[22] W. Zhao, P. Salame, V. Herlédan, F. Launay, A. Gédéon, Proceedings of the Fourth International Mesostructured Materials Symposium, Cape Town, May 1st to 4th, 2004, pp. 154-155.

[23] K. Wilson, A.F. Lee, D.J. Macquarrie, J.H. Clark, Appl. Catal. A: Gen. 228 (2002) 127.

[24] D. Margolese, J.A. Melero, S.C. Christiansen, B.F. Chmelka, G.D. Stucky, Chem. Mater. 12 (2000) 2448.

[25] W.M. van Rhijn, D.E. De Vos, B.F. Sels, W.D. Bossaert, P.A. Jacobs, Chem. Commun. (1998) 317.

[26] J. Pérez-Pariente, I. Diaz, F. Mohino, E. Sastre, Appl. Catal. A: Gen. 254 (2003) 173.

[27] J.G.C. Shen, R.G. Herman, K. Klier, J. Phys. Chem. B 106 (2002) 9975.

[28] M.H. Lim, C.F. Blanford, A. Stein, Chem. Mater. 10 (1998) 467.

[29] I. Díaz, C. Marquez-Alvarez, F. Mohino, J. Pérez-Pariente, E. Sastre, J. Catal. 193 (2000) 283.

[30] M. Boveri, J. Agúndez, I. Díaz, J. Pérez-Pariente, E. Sastre, Collect. Czech. Chem. Commun. 68 (2003) 1914.

[31] V. Dufaud, M.E. Davis, J. Am. Chem. Soc. 125 (2003) 9403.

[32] D. Das, J.F. Lee, S. Cheng, Chem. Commun. (2001) 2178.

[33] D. Das, J.-F. Lee, S. Cheng, J. Catal. 223 (2004) 152.

[34] M. Alvaro, A. Corma, D. Das, V. Fornés, H. Garcia, Chem. Commun. (2004) 956.
[35] I. Díaz, F. Mohino, J. Pérez-Pariente, E. Sastre, Appl. Catal. A: Gen. 205 (2001) 19

[36] I. Díaz, C. Márquez-Alvarez, F. Mohino, J. Pérez-Pariente, E. Sastre, J. Catal. 193 (2000) 295.

[37] Y. Li, W. Zhang, L. Zhang, Q. Yang, Z. Wei, Z. Feng, C. Li, J. Phys. Chem. B 108 (2004) 9739.

[38] R.K. Iler, Chemistry of Silica, John Wiley \& Sons, Inc., 1979.

[39] A.P. Legrand, The Surface Properties of Silicas, John Wiley \& Sons, Inc., 1998.

[40] H.E. Bergna (Ed.), The Colloid Chemistry of Silica (Adv. Chem. Ser. 234), American Chemical Society, Washington, DC, 1984.

[41] J.P. Gallas, J.C. Lavalley, A. Burneau, O. Barrès, Langmuir 7 (1991) 1235.

[42] F. Chiker, J.P. Nogier, F. Launay, J.L. Bonardet, Appl. Catal. A: Gen. 259 (2004) 153.

[43] F. Algarra, A. Corma, H. Garcia, J. Primo, Appl. Catal. A: Gen. 128 (1995) 119.

[44] T. Li, S. Cheng, J.F. Lee, L.Y. Jang, J. Mol. Catal. A: Chem. 198 (2003) 139.

[45] D.J. Macquarie, S.J. Tavener, M.A. Harmer, Chem. Commun. (2005) 2363.

[46] D. Huang, M. Han, J. Wang, Y. Jin, Chem. Eng. J. 88 (2002) 215.

[47] G.D. Yadav, N.S. Asthana, Appl. Catal. A: Gen. 244 (2003) 341.

[48] R. Selvin, G.R. Rajarajeswari, L. Selva Roselin, V. Sadasivam, B. Sivasankar, K. Rengaraj, Appl. Catal. A: Gen. 219 (2001) 125. 